\title{
Application of Silylether and Silylester Polymer for Chemical Amplification System
}

\author{
Toshiaki Aoai, Yoshimasa Aotani, Akira Umehara, \\ and Tadayoshi Kokubo \\ Fuji Photo Film Co., Lta. \\ 4000 Kawashiri Yoshida-cho Haibara-gun Shizuoka, \\ Japan
}

A Chemical Amplification system using silylether and silylester polymers as an acid labile compound was investigated. The effects of their structural parameters were examined in terms of their acid catalyzed decomposition rates. A bulkiness of the substituents on $\mathrm{Si}$ atom was the dominant parameter for these silicone polymers. The results supported the proposed mechanism of the acid decomposition that $s_{N} 2$ type nucleophilic attack of water to $s i$ atom is involved as the rate determining step. Disulphone compounds were examined for their usefulness as a photoacid generator to be combined with these silicone polymers. The disulphones desirably exhibited a rapid absorption bleaching with acid generation upon deep UV irradiation. A three components chemical amplification composition, utilizing the disulphones, the silicone polymers as a dissolution inhibitor and a novolac resin, was tested lithographically, and was proved to work as a deep UV positive photoresist. 


\section{Introduction}

The exposure light source in microlithography is moving to shorter wavelength down to deep UV region in accordance with continuous trend to higher integration in semiconductor devices. Conventional positive photoresist of diazonaphthoquinone and novolac system (DQN), however, does not work well in this region due to too high optical absorption and its insufficient bleaching. Furthermore, DQN resist has a limitation in improving its photospeed because of the lack of the effective photochemical sensitization as well as the quantum yield which never exceeds the unity.

The new photochemistry, "Chemical Amplification" (CA), provided by a photoacid generator and an acid labile compound, appears to be more promising for the purpose[1]. The system provides a catalytic reaction succeeding to the photochemical reaction, which allows a higher photospeed and thereby a reduction in the optical absorption of the film which is dominated by the photo-active compound loaded. A larger freedom of the system in contrast with DQN resists on choosing the variety of compounds and their combinations is another advantage.

The authors have reported the CA system which utilizes silylether polymers[2]. This system has a lot of convenience upon utilization. The polymers provide a rapid hydrolysis by acids and a wide capability in the tuning of the hydrolyzing rate by modification in their chemical structures. The ease of syntheses of the polymers is also an advantage. Three components CA system utilizing the silicone polymers as a dissolution inhibitor of a novolac binder is particularly of importance in practice. The authors will present, in this paper, recent results in the study of this system with a wider variety of the compounds as well as an expansion of the silicone polymer to silylesters. A result with a preliminary application of the system to a deep UV resist will also be reported.

\section{Experiments}

\section{2-1) Syntheses of Silylether Polymers:}

Diol compounds were dissolved in an aprotic solvent (e.g., ethyl acetate), and were added with a double molar amount of pyridine. An equimolar amount of dichlorodialkyl-silanes were added dropwise to the solutions at room temperature. The solutions were filtered for removal of the pyridine $\mathrm{HCl}$ salt after the reaction for 3 hours at $50^{\circ} \mathrm{C}$ with stirring. The solutions were then washed with a $58 \mathrm{NaHCO}_{3}$ aqueous solution, and again with a saturated brine, and were finally dried with anhydrous $\mathrm{Na}_{2} \mathrm{SO}_{4}$. The resulting silylether polymers were obtained by evaporating the filtrate. Silylether polymers with molecular weights between 2,000 and 20,000 in weight average (GPC, based on polystyrene standard) were obtained. 
2-2) Syntheses of Silylester Polymers:

Monomer syntheses: Trialkylchlorosilanes were added dropwise at room temperature to the DMF solution of methacrylic acid with a double molar amount of imidazole. The solutions were kept stirring for 5 hours at $50^{\circ} \mathrm{C}$ for the completion of the reaction. The reaction products, trialkylsilyl methacrylates, were obtained by extraction with ethyl acetate from the reaction mixture added with water, followed by drying of the extracts and isolation with vacuum distillation.

Polymerizations: The trialkylsilyl methacrylates were dissolved with comonomers into dioxane up to $30 \mathrm{wt} / \mathrm{s}$ solution, then were heated to $70^{\circ} \mathrm{C}$ with stirring under a nitrogen stream. An initiator, 2, 2'-azobis(2,4dimethylvaleronitrile) $(0.2$ mole $\&$ based on total monomers) was added to the solutions, then the polymerization was carried out for 8 hours at $70^{\circ} \mathrm{C}$. The resulting polymers were isolated by precipitation of the reaction mixtures into water. The precipitates were then filtered out and dried. Silylester polymers with molecular weights between 10,000 and 100,000 were obtained.

\section{2-3) Determination of Acid decomposition Rate Constants:}

Acids (e.g., HCl) were added to silicone model compounds dissolved in a $9 / 1$ mixture of acetonitrile/water. The acid decompositions of the compounds at $25^{\circ} \mathrm{C}$ were monitored with gas chromatographic analysis of the solutions by time to time samplings. The acid cc zentrations were determined by the pH values of the solutions. The rate constants of the acid decompositions were calculated by plotting the concentration of the starting compounds against the time using pseudo-first order approximation.

\section{2-4) Determination of Dissolution Rates:}

The following photosensitive compositions were dissolved in coating solvent, ECA, and were spin coated onto a bare silicon wafer to give 1.0 micron film thickness after prebake at $90^{\circ} \mathrm{C}$ for $90 \mathrm{sec}$. The wafer was then exposed to either 365 or $254 \mathrm{~nm}$ light. and was put into the Perkin-Elmer's DRM for monitoring the dissolution rate of the coated film. The baking after the exposure (PEB) was not applied. A tetramethylammonium hydroxide (TMAH) aqueous solution with 2.38 wto was used on determining the dissolution rates.

\begin{tabular}{lc}
\multicolumn{3}{c}{ Composition of the Photosensitive Layer(wt\%) } \\
\hline Silicon polymer & 26.3 \\
Acid precursor & 3.3 \\
Cresol-novolac resin & 70.4 \\
$(\mathrm{~m} / \mathrm{p}=4 / 6$, Dissolution rate $=178 \mathrm{~A} / \mathrm{sec})$
\end{tabular}




\section{2-5) Lithographic Patternings:}

Deep UV resist compositions were prepared, and were spin coated onto a bare silicon wafer in the same manner as above. The wafer was then exposed to $254 \mathrm{~nm}$ light through a contact mode mask having line and space patterns. Puddle development using 2.388 TMAH solution was applied to the wafer immediately after the exposure.

\section{Results and Discussion}

\section{3-1) Influence of Silicone Polymer Structure to Acid Decomposability:}

The decompositions of silylether and silylester induced by acid are considered to proceed with the mechanism as shown in Scheme 1 . A photo-generated acid, at first, protonates to the oxygen atom of silylether or silylester group, then a nucleophilic attack of water to $\mathrm{Si}$ atom $\left(\mathrm{S}_{\mathrm{N}} 2\right.$, type reaction) takes place resulting in the cleavage of the si-O bond. A proton is thereby reproduced and utilized catalytically. A heating following to the exposure generally accelerates the decomposition.

In order to find out higher photospeed system without the heating step, the effects of structural parameters of the.silicone polymers on acid decomposability were studied by the following experiments using model compounds.

Steric effects around the silylether and silylester moieties were examined at first. Figs. 1 and 2 give the results. The rate constants for acid decompositions of model compounds are plotted as a function of the Taft's steric parameter, Es[3], of their substituents. The decomposition rate was remarkably lowered with increasing bulkiness of the substituents, $R$, and the results thereby supported the mechanism on scheme 1 which implied the steric effect in the $\mathrm{s}_{\mathrm{N}} 2$ inversion. The following two results should also be noted on knowing the effect of structural parameters in conjunction with the decomposition mechanism.

Fig. 3 shows the effect of introduction of hydrophilic ethyleneoxy chains to the model compounds. The decomposition rate was increased according to the extension of the ethyleneoxy chain length. This is probably because of more rapid nucleophilic attack of water facilitated by the hydrophilic moieties.

Fig. 4 shows the effect of substituents of phenoxy group in the model compounds. An electron withdrawing substituent at para position, which lowers the pKa value of the phenolate, was found to accelerate the decomposition.

Among these parameters, the steric hindrance of the substituents around $S i$ atom exerted a greater influence on the acid hydrolysis of silylether and silylester compounds. Avoiding the PEB step in the process, the decomposition 


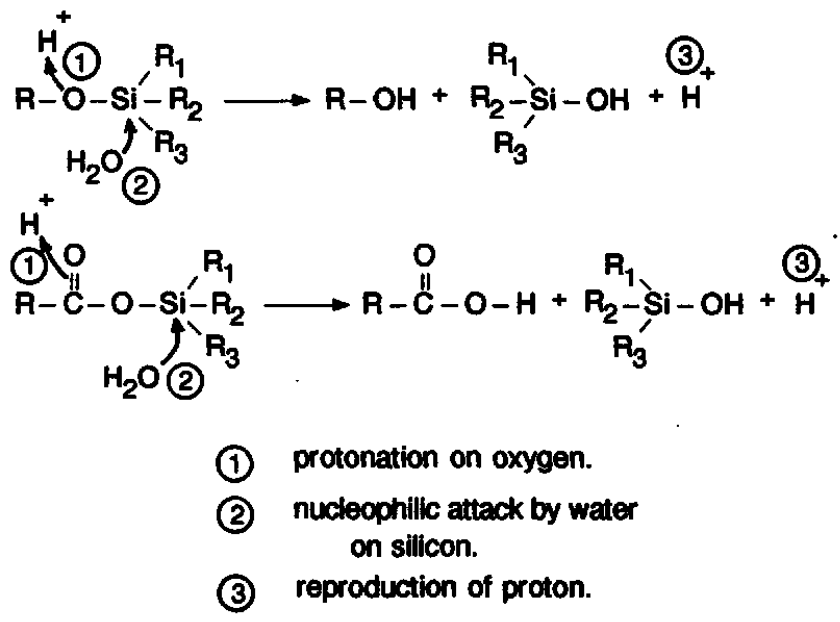

Scheme 1 Mechanism of acid hycrolysis of silylether and silylester compounds

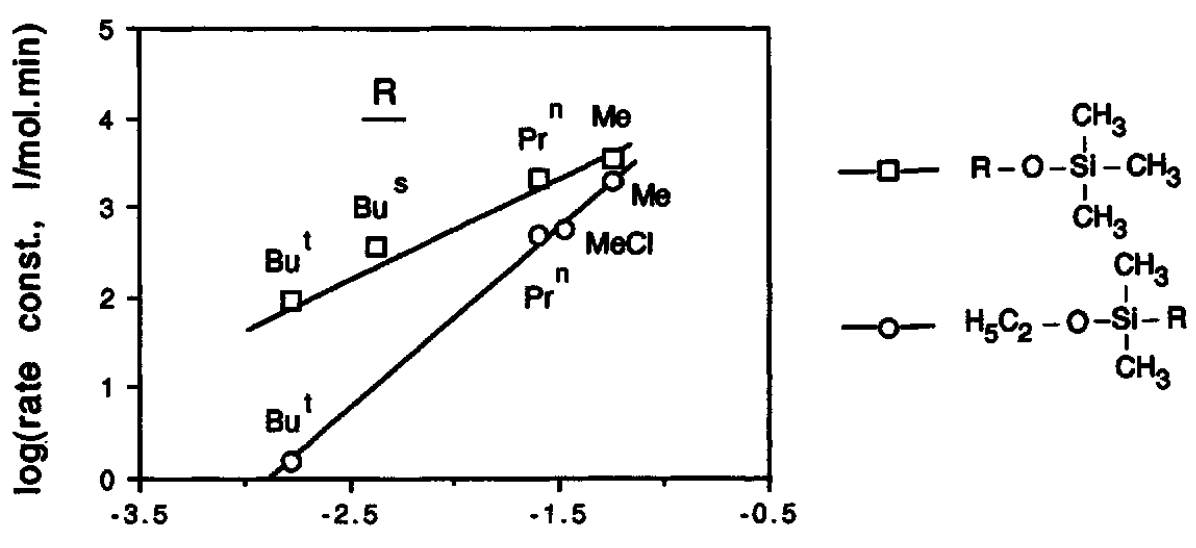

Es value

Fig.1 Steric effect on hydrolysis of silylether compounds.

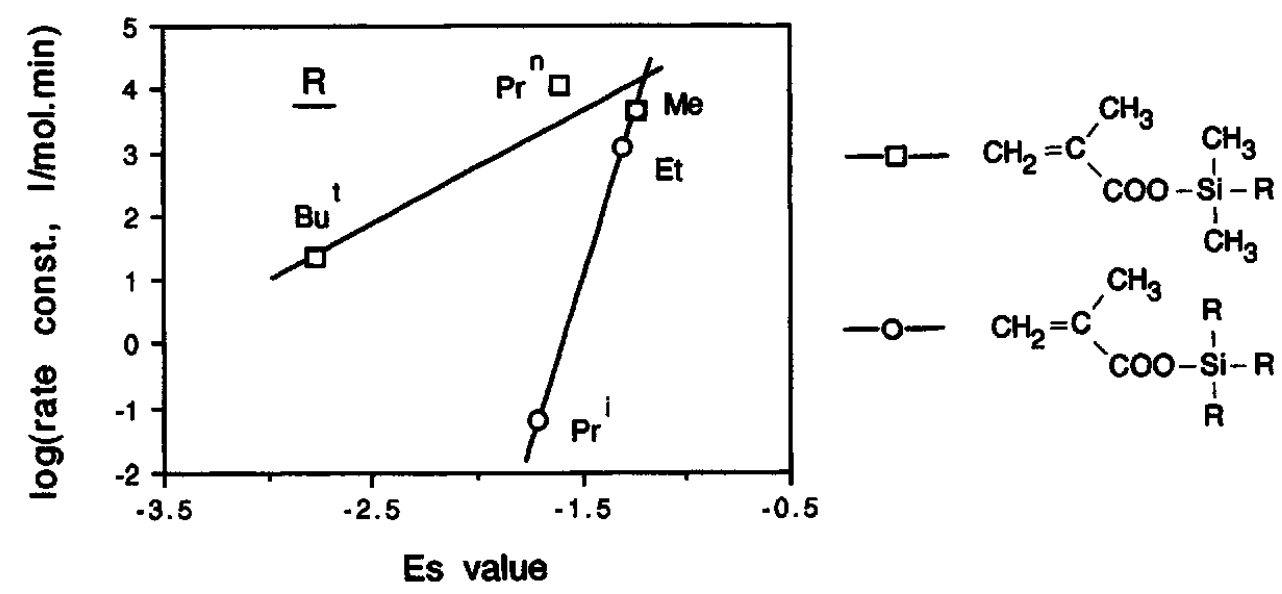

Fig.2 Steric effect on hydrolysis of siblester compounds. 


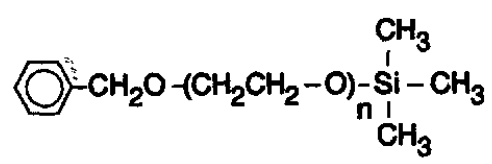

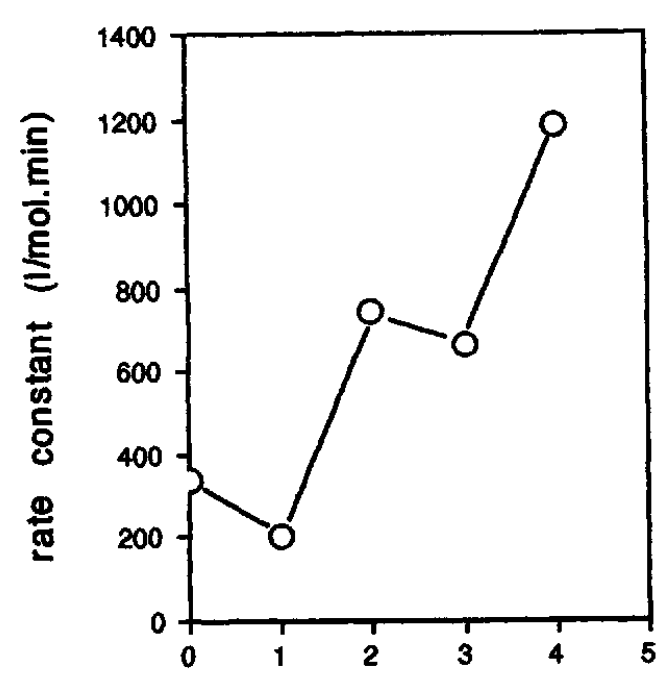

length of ethyleneoxy group, $n$
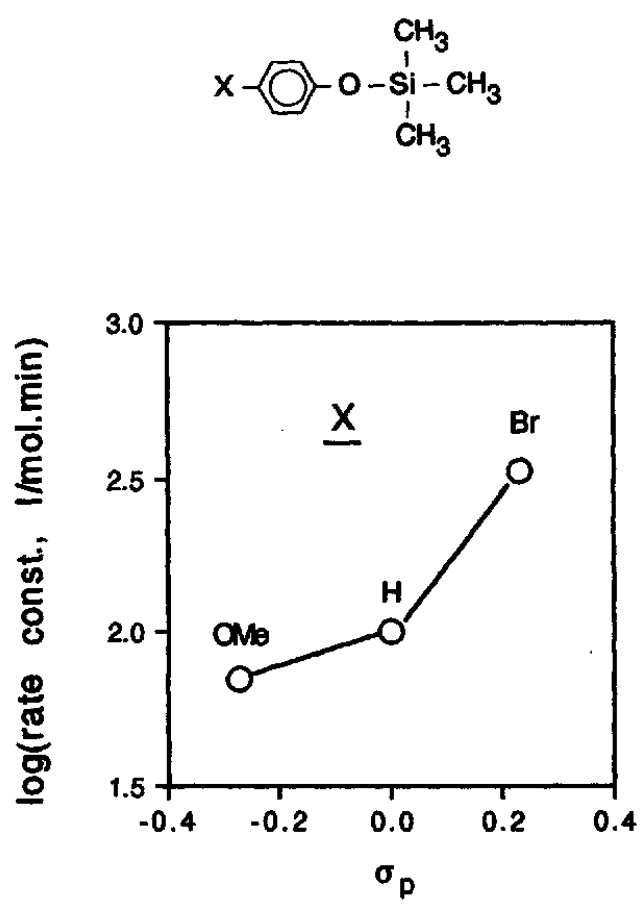

Fig.4 Substituent effect on hydrolysis of phenolsilylethers.

Fig.3 Hydrophilic effect on hydrolysis of silylether compounds.

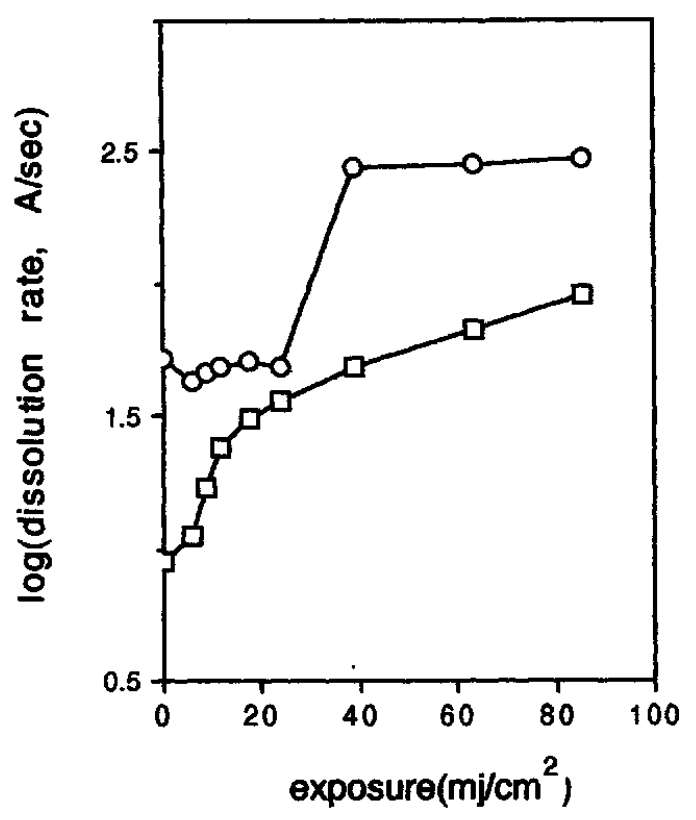

Fig.5 Change of dissolution rate on exposure. (silylether polymer)

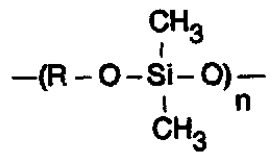

R: $\quad-\mathrm{CH}_{2}-\mathrm{O}-\mathrm{CH}_{2}-1-\left(\mathrm{CH}_{2} \mathrm{CH}_{2}-\mathrm{O}\right)_{4}-(50 / 50)$

$-\mathrm{CH}_{2} \mathrm{CH}_{2}-\mathrm{OCONH} \mathrm{O}_{\mathrm{NHCOO}-\mathrm{CH}_{2} \mathrm{CH}_{2}-\quad \text { (2) }}^{\mathrm{CH}_{3}}$

(acid precursor)

(Q) 
rate directly determines the photospeed of the system. It is thus possible to modify the photospeed of the system as desired by changing this steric parameter of the silicone polymers. It was observed, for example, that the photospeed became four times faster by altering the substituents of silylether polymers from a bulkier n-hexyl to methyl.

\section{3-2) Dissolution Inhibition by Silicone Polymers:}

The silylether and silylester polymers work as dissolution inhibitors of a novolac binder in alkaline developer. The efficiency of the inhibition is affected by the chemical structures of these polymers. Although the relationship between the structure of the inhibitor and the inhibition capability is not fully understood, the dominating factors are not necessarily limited by silyl moieties but the structures and physical properties of the whole molecule. For example, the silylether polymer (2) containing a carbamate group, which generates a strong hydrogen bond to novolac, provided stronger inhibition than the polymer (1 1 ) in Fig. 5. Table 1 gives another example where a decreased inhibition is demonstrated with the polymer having more hydrophilic co-monomer unit. Changes in the co-monomer structure also affected to the dissolution inhibition.

It is important to design the structure of the silicone polymers to give a reasonable dissolution inhibition which matches to the dissolution rate of the binder system on designing a practical photoresist system.

\section{3-3) Disulphone Compounds as Acid Precursor:}

Different types of photoacid generators can be utilized for this system, e.g., s-triazine or 1,3,4-oxadiazole compounds bearing trihalomethyl groups, $\mathrm{PF}_{6}$ or AsF 6 salts of triarylsulphonium or diaryliodonium compounds, and Nsulphonyloxyimide compounds. All these compounds are known to generate acids such as hydrochloric acid, perfluoro Lewis acid and sulphonic acid. Disulphone compounds are another class of the photoacid generators as a sulphinic acid source. The CA system which involved the combinations of disulphone compounds and silicone polymers was investigated, in particular for deep uv application.

Disulphone compounds were found to decompose quickly upon deep UV irradiation and lose efficiently their absorption in this region. The bleaching efficiencies were even higher than a diazonaphthoquinone compound (Fig. 6). As shown in Fig. 7, a structural modification study with altering substituents proved the capability of absorption band tuning (e.g., in the range of $255-338 \mathrm{~nm}$ for the absorption maxima).

Disulphone compounds were also found to work themselves as a dissolution inhibitor of alkaline soluble polymers additionally to the silicone polymers. A 10 wto addition of the compound (c) in Fig. 7 to a novolac binder exhibited the 
Table 1 Dissolution rate of photosensitive layer containing silylester polymers

\begin{tabular}{|c|c|c|c|c|c|}
\hline \multirow{2}{*}{ polymer } & \multicolumn{2}{|c|}{ comonomer $(\mathrm{mol} \%)$} & \multirow{2}{*}{$\bar{M} w$} & \multirow{2}{*}{$\mathrm{Tg}(\mathrm{C})$} & \multirow{2}{*}{$\begin{array}{c}\text { dissolution rate } \\
\text { (A/sec) }\end{array}$} \\
\hline & $A(a)$ & $\mathrm{B}$ (b) & & & \\
\hline (3) & St $(80)$ & - & 15000 & 96 & $<3.3$ \\
\hline (4) & St (50) & HEMA (30) & 19000 & 95 & 8.9 \\
\hline (5) & St (50) & MAA (30) & 15000 & 157 & 14.6 \\
\hline (6) & BzMA (80) & - & 27000 & 73 & 6.7 \\
\hline$(7)$ & MMA (80) & $=$ & 20000 & 123 & 14.0 \\
\hline
\end{tabular}

St : styrene BzMA : benzyl methacrylate MMA : methyl methacrylate HEMA : 2-hydroxyethyl methacrylate MAA : methacrylic acid
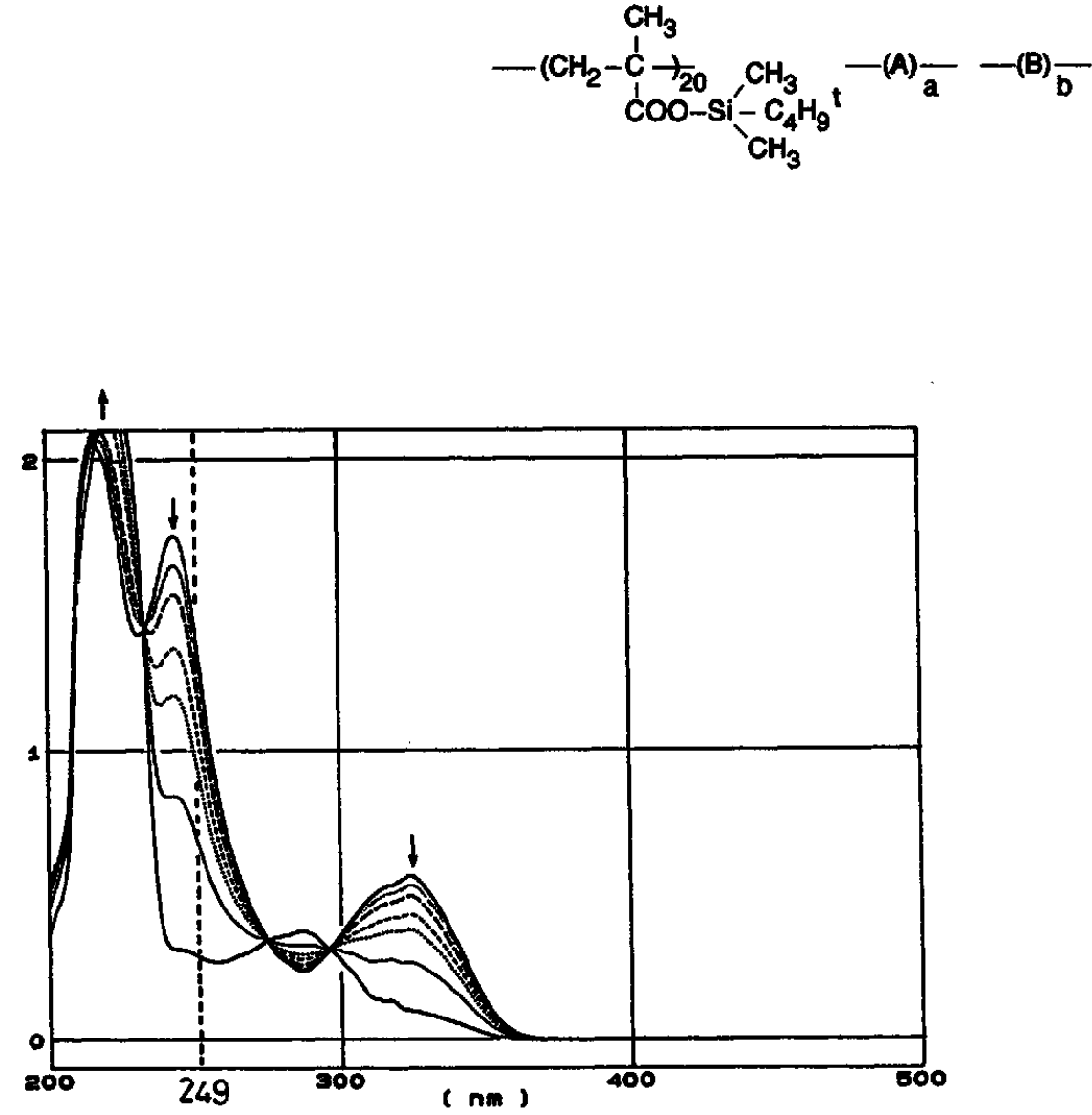

(disulphone compound)

$\mathrm{Cl}-\mathrm{O}-\mathrm{SO}_{2}-\mathrm{SO}_{2}-\mathrm{O}$

(solvent) THF

(exposure) $249 \mathrm{~nm}$

Fig.6 Change of absorption spectra on exposure. 
reduction for dissolution rate of the novolac to a thirtieth, for example.

The photolysis of a disulphone compound is believed to proceed with the mechanism as shown in scheme 2. Two equivalences of sulphinic acid are generated through one photolytic reaction of the molecule. The result of INDO-CI calculation of a typical disulphone molecule well supported the mechanism. Quantum yields of the photolyses of disulphone compounds in THF solution were determined to be in the range of $0.2-0.6$, depending on the differences in their structures.

\section{3-4) Photo-imaging using Disulphone / silicone Polymer System:}

The photosensitive compositions consisting of the disulphone compounds and the silicone polymers admixed with novolac resin were examined for their dissolution characteristics in alkaline by using DRM. Figs. 8 and 9 give the results of the systems involving silylether and silylester polymers respectively. The increases in dissolution rate upon $254 \mathrm{~nm}$ exposure were observed for these systems, and the systems were thus proved to be capable of positive mode imaging with deep UV exposure.

Fig. 10 shows an example of SEM pictures obtained through a preliminary work for deep UV lithographic imaging of the above system. The result demonstrates that the system is able to provide a material for deep UV lithography, although a sloping at the bottom of the image is still seen in the picture probably due to the insufficient optimization in the formulation.

\section{Conclusions}

The CA system utilizing silylether and silylester polymers as an acid labile component was proposed.

The most effective structural parameter for acid decomposition in these silicone polymers was the steric hindrance of the substituents on si atoms. The introduction of hydrophilic moieties or of electron withdrawing groups at para position of phenoxy group attaching to the si atom was also found to enhance the decomposition. The results indicated a potential of this system on achieving a high photospeed without the $\mathrm{PEB}$ step in the process.

Disulphone compounds were found to be useful as a photoacid generator for CA systems. The disulphones also provided an inhibition effect to novolac dissolution as well as a rapid absorption bleaching upon deep UV irradiation. The three components $C A$ composition using the disulphones in combination with the silicone polymers admixed with novolac binder was evaluated lithographically, and was proved to be a good candidate for deep uv positive photoresist system having a high photospeed. 


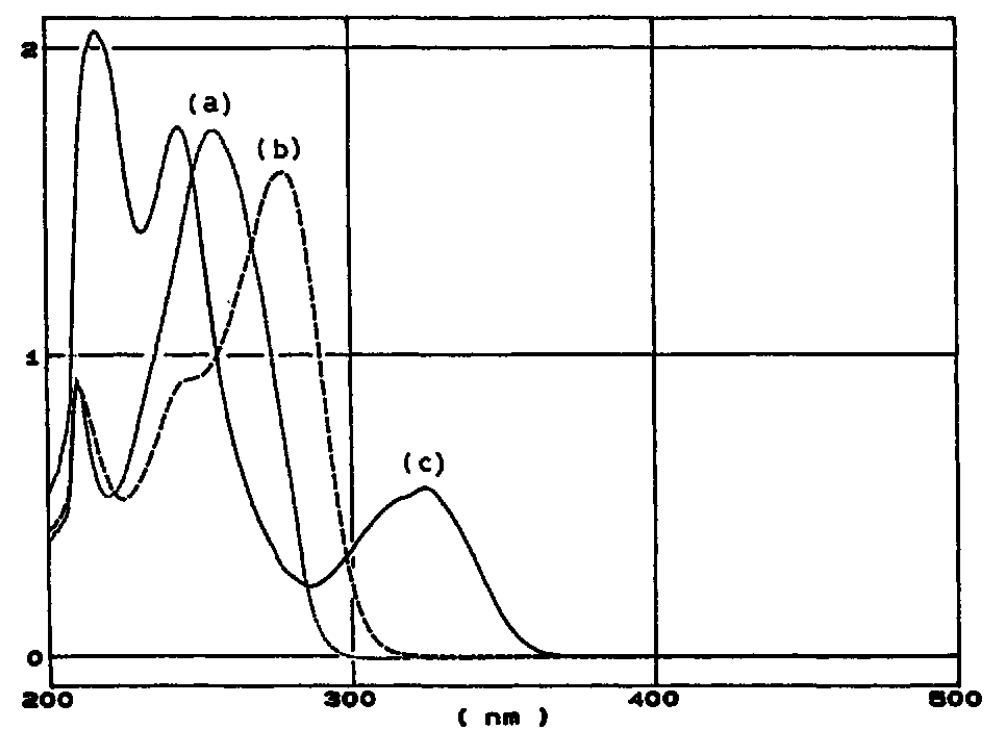

Fig.7 Absorption spectra of disulphone compounds. (a): $\mathrm{Cl}-\mathrm{O}-\mathrm{SO}_{2}-\mathrm{SO}_{2}-\mathrm{O}-\mathrm{CH}_{3}$

$\lambda \max 256 \mathrm{~nm}$ $\varepsilon \quad 27800$

(b):

$$
\begin{array}{cc}
\mathrm{Cl}-\mathrm{O}-\mathrm{SO}_{2}-\mathrm{SO}_{2}-\mathrm{O}-\mathrm{OCH}_{3} \\
\lambda \max & 279 \mathrm{~nm} \\
\varepsilon & 27300
\end{array}
$$

(c):

$$
\begin{aligned}
& \mathrm{Cl}-\mathrm{O}-\mathrm{SO}_{2}-\mathrm{SO}_{2}-\mathrm{O} \\
& \lambda \max \quad 324 \mathrm{~nm} \\
& \varepsilon \quad 10200
\end{aligned}
$$

(soluvent) THF

$$
\begin{aligned}
& A r_{1}-\mathrm{SO}_{2}-\mathrm{SO}_{2}-\mathrm{Ar}_{2} \stackrel{\mathrm{h}_{v}}{\longrightarrow} \mathrm{Ar}_{1}-\mathrm{SO}_{2} \bullet+\mathrm{Ar}_{2}-\mathrm{SO}_{2} \bullet \\
& \stackrel{\mathrm{H} \text {-donar }}{\longrightarrow} \mathrm{Ar}_{1}-\mathrm{SO}_{2} \mathrm{H}+\mathrm{Ar}_{2}-\mathrm{SO}_{2} \mathrm{H}
\end{aligned}
$$

Scheme 2 Mechanism of photodecomposition of disulphone compounds
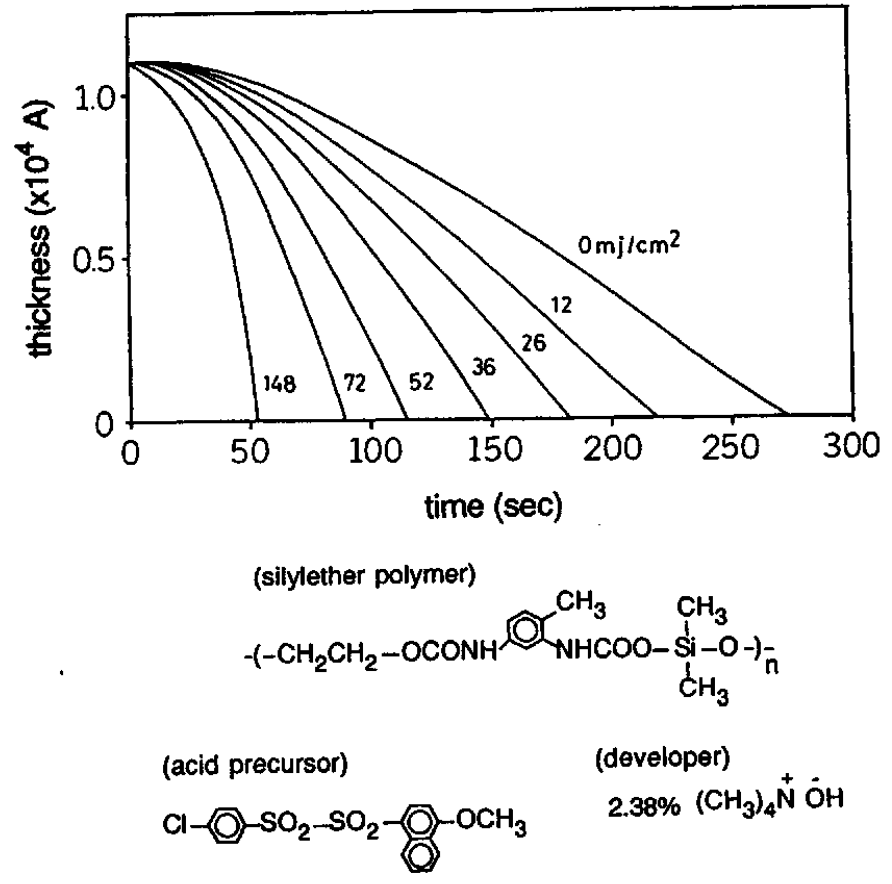

Fig.8 Dissolution kinetics on system of silylether and disulphone compounds. 
J. Photopolym. Sci. Technol., Vol. 3, No.3, 1990

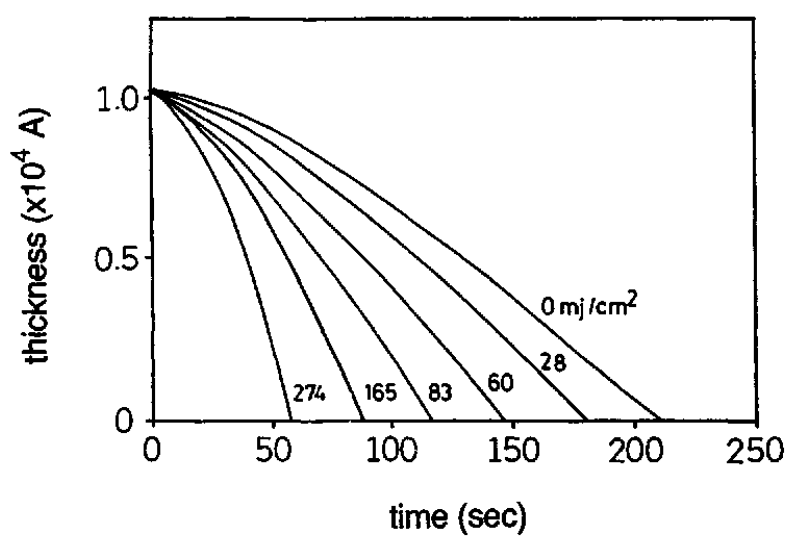

(silylester polymer)

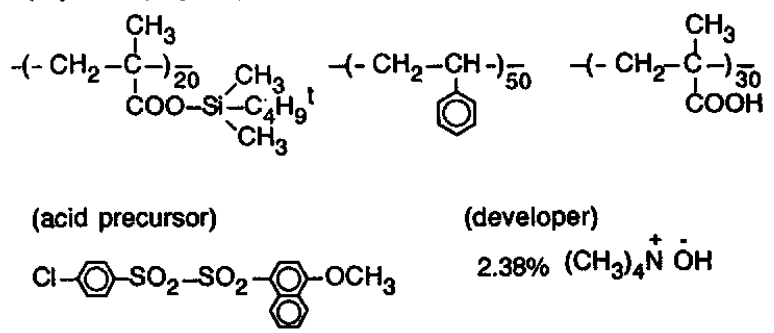

Fig.9 Dissolution kinetics on system of silylester and disulphone compounds.

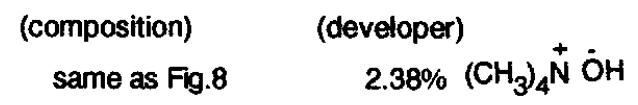

Fig.10 SEM photograph of $1.0 \mathrm{um} L \& S(254 \mathrm{~nm}$, contact, $54 \mathrm{mj} / \mathrm{cm} 2)$

399 


\section{References}

[1]. For example, a)H.Ito and C.G.Willson, Polym. Eng. Sci.,23,1012(1983). b) J.M.J.Frechet, E.Eicher, H.Ito and C.G.Willson, Polymer,24,995(1983). C) H.Ito and C.G.Willson, ACS Symp. Ser., 242, 11 (1984). d)C.E.Osuch, K.Brahim, F.R.MCFarland, A.Mooring and C.J.Wu, SPIE, 631, 68 (1986).e)M.J.O'Brien, J.V.Crivello, SPIE, 920, 42 (1988). f)F.M.Houlihan, A.Shugard, G.Gooden and E.Reichmanis, Macromolecules,21,2001(1988). g) H.Ito and M. Ueda, Macromolecules, 21,1475(1988). h)T.Yamaoka, M.Nishiki, K.Koseki and M.Koshiba, Technical Papers, p27, Regional Technical Conf., Oct.30-Nov.2,1988, Ellenville, New York (Soc. Polym. Eng.).

[2]. a)T.Aoai, Y.Aotani, A.Umehara, N.Matsuda and A.Kamiya, Technical Papers, p209, The 4th Conf. Photopolymer Sci. Tech., 1985, Tokyo. b) T.Aoai, A.Umehara, A.Kamiya, N.Matsuda and Y.Aotani, Polym. Eng. Sci.,29,887(1989).

[3]. Newman,Ed., Steric Effect in Org. Chem.,598(1956). 